\title{
Panorama da Inovação Organizacional em países selecionados: uma análise de indicadores da Community Innovation Survey (CIS) e Pesquisa de Inovação (PINTEC)
}

\author{
Carlos Eduardo de Oliveira (UFU) carlos.oliveira@ufu.br \\ Ana Paula Macedo de Avellar (UFU) anaavellar@ufu.br
}

\begin{abstract}
Resumo
O objetivo deste estudo foi apresentar um panorama das Inovações Organizacionais consideradas mais relevantes realizadas pelas empresas dos países da Comunidade Europeia (CE) e das empresas situadas no Brasil. Utilizou-se como base de dados as empresas situadas nos países pertencentes à CE nas edições 6 (2006-2008) e 7 (2008-2010) da Community Innovation Survey (CIS) e para as empresas situadas no Brasil foram utilizadas as edições de 2008 e 2011 da Pesquisa de Inovação (PINTEC). Os principais resultados apontam que os países da CE que possuem maior quantidade de empresas pesquisadas e maior quantidade de empresas que realizaram inovações, foram os que realizaram menos IO em relação aos demais. Considerando-se um alto percentual de empresas que realizam inovações e o baixo percentual de empresas que realizam somente IO ou somente inovações de produto ou somente de processo, sugere-se que essas empresas realizaram mais de um tipo de inovação concomitantemente. Observou-se também que o percentual das empresas situadas no Brasil, que realizam somente IO e/ou de marketing é superior ao das empresas situadas na CE. Outro aspecto observado sugere que as empresas que realizaram inovações dos diversos tipos em conjunto, com maior intensidade, em comparação com a realização de somente um tipo de inovação.
\end{abstract}

Palavras-chave: Inovação; Inovação Organizacional; Community Innovation Survey; Pesquisa de Inovação.

\begin{abstract}
The aim of this study was to present an overview of the most relevant considered organizational innovations made by companies of European Community countries (EC) and companies located in Brazil. Was used as database companies located in countries belonging to the EC on issues 6 (20062008) and 7 (2008-2010) of the Community Innovation Survey (CIS) and for companies located in Brazil have used the 2008 editions and 2011 Innovation Research (PINTEC). The main results show that the EC countries that have the greatest number of companies surveyed and a larger number of enterprises that have innovations were those who performed less IO than the other. Considering a high percentage of companies that carry out innovation and the low percentage of companies that only perform IO or only product innovations or process only, it is suggested that these companies held more than one type of innovation concurrently. Also noted is that the percentage of companies located in Brazil, performing only IO and / or marketing is higher than the companies located in the EC. Another aspect observed suggests that companies that made innovations of various types together with higher intensity compared to the performance of only one type of innovation.
\end{abstract}

Keywords: Innovation; Organizational Innovation; Community Innovation Survey; Innovation Survey.

Área 5: Inovação, competências e competitividade

JEL: O30 


\section{Introdução}

O atual cenário econômico internacional apresenta condições de ampla concorrência entre empresas e produtos por ela fabricados. A busca por diferenciação torna-se necessária num ambiente onde a competição por participação em um mercado é acirrada. A realização de inovação de produto, processo, organizacional e ou de marketing tornaram-se relevantes, por proporcionar vantagem competitiva, bem como por provocar impacto favorável no desempenho financeiro. $\mathrm{O}$ desempenho inovador é visto na literatura como um dos mais importantes motores do desempenho organizacional, graças à formação de um clima de aprendizagem organizacional e ou orientação com os esforços contínuos de melhorias, renovações, aprender com as falhas e adaptação às rápidas mudanças no ambiente competitivo (GUNDAY e outros, 2011).

Schumpeter (1982) afirma que a inovação pode ser entendida como a introdução de novos produtos, métodos de produção, mercados, fontes de fornecimento e formas de organização. As grandes indústrias ainda respondem pela maioria das inovações na maior parte dos setores industriais, mas essas inovações podem ser usadas por outras empresas (PAVITT, 1984). A obtenção de tecnologias novas e avançadas é um fator importante para a posição competitiva de um país ou região (FREEMAN, 1987; PORTER, 1990).

Outro achado importante refere-se à importância da inovação tecnológica para o comportamento inovação organizacional. Isso aponta para as fortes complementaridades entre inovações tecnológicas e organizacionais, e corrobora com a literatura enfatizando o estreito entrelaçamento de ambos os tipos. (GANTER e HECKER, 2013). A Inovação Organizacional (IO) refere-se a mudanças que ocorrem na estrutura gerencial da empresa, na forma de articulação entre suas diferentes áreas, na especialização dos trabalhadores, no relacionamento com fornecedores e clientes e nas múltiplas técnicas de organização dos processos de negócios (TIGRE, 2006).

Apesar de sua reconhecida importância, a IO geralmente tem recebido menos atenção na literatura de inovação tecnológica (SAPPRASERT e CLAUSEN, 2012). Considerando a literatura descritiva e empírica existente, Gunday e outros (2011) defendem que as IO na forma de melhorias estruturais que levam à melhoria da coordenação intra-organizacional e mecanismos de cooperação, contribuirão para a formação de um ambiente interno adequado para florescimento dos outros tipos de inovações.

Considerando a relevância da IO para as empresas, o objetivo deste estudo é apresentar o panorama das IO consideradas de maior relevância para as empresas situadas nos países da Comunidade Europeia (CE) e das empresas situadas no Brasil. Cabe-se observar as relações entre inovação (técnica e administrativa) e o desempenho organizacional, observando-se que a adoção de um grande número de inovações técnicas e administrativas leva a uma maior eficiência organizacional (SUBRAMANIAN e NILAKANTA, 1996). Acredita-se também que a adoção da IO facilita a aprendizagem (SUBRAMANIAN e NILAKANTA, 1996).

Um fator que inibe o progresso teórico no campo é a falta de pesquisadores nas áreas de inovação e de estudos organizacionais que desenvolvem pesquisas em conjunto (LAM, 2005). O desafio de estudar a IO (ou para essa matéria qualquer outro tipo de ativo intangível) é que não há uma definição clara do que é a IO, como medi-la, ou a melhor forma de quantificar a sua contribuição para a saída, atual ou futura (LYNCH, 2007). Apesar de sua reconhecida importância, inovação organizacional geralmente tem recebido menos atenção na literatura de inovação tecnológica. (SAPPRASERT e CLAUSEN, 2012). Esses aspectos contribuem para estimular o desenvolvimento de pesquisas acerca da IO.

Este estudo está estruturado em cinco seções. A primeira seção é formada desta introdução; a segunda seção abarca a plataforma analítica acerca da inovação; a terceira seção apresenta os procedimentos metodológicos; a quarta seção é composta pelos resultados do estudo e a quinta seção apresenta as considerações finais. 


\section{Plataforma analítica: breve histórico da inovação e alguns aspectos da IO}

Alguns acontecimentos ocorridos no mundo foram marcantes para a evolução da sociedade em geral. Certas mudanças na fabricação dos produtos, novos elementos materiais e formas de organização provocaram a quebra de diversos paradigmas existentes. Considerando a relevância dos fatos históricos que provocaram importantes inovações em determinada época e local, este breve histórico tem por objetivo destacar algumas inovações que provocaram importantes mudanças, principalmente nas firmas.

A Revolução Industrial ocorrida por volta do século XVIII teve um importante destaque na economia do Ocidente. Nessa época, a fabricação de algum produto era realizada de forma artesanal, não utilizando, portanto, de máquinas e processos organizacionais que pudessem contribuir para o aumento da produtividade e redução de custos. Importantes inventos contribuíram para a mudança radical dos processos produtivos (destaca-se principalmente a automação dos processos) e na divisão do trabalho (proporcionando a especialização das atividades realizadas pelos operários). Entre as várias invenções desta época, destacam-se a roda d'água, máquina a vapor e o condensador de energia. Carlota Perez (2009) destaca a primeira Revolução Industrial como o primeiro surto/onda de desenvolvimento industrial ocorrido no mundo.

Diversas inovações introduzidas na época foram fundamentais para a redução das horas necessárias para a realização de uma tarefa, seja na produção de um item (produto e processo), como na realização de uma atividade organizacional. Destaca-se o surgimento de algumas inovações na indústria têxtil que proporcionaram redução dos custos de produção, aumento da produção, redução do preço de venda e expansão do mercado. Com isso, à medida que as novas tecnologias transformam os padrões de trabalho e de consumo, também transformam a forma como o trabalho e as empresas estão organizados, e isso estabelece novos princípios de organização (PEREZ, 2009).

A Grã-Bretanha tornou-se um modelo de referência para os outros países, por conta de sua superioridade organizacional e tecnológica de suas indústrias e por volta do ano de 1880, ela era responsável por cerca de $40 \%$ das exportações mundiais de produtos manufaturados, contra apenas $6 \%$ dos Estados Unidos; sua produtividade do trabalho era 14\% maior que a das empresas dos EUA (TIGRE, 2005).

A segunda Revolução Industrial, ocorrida na segunda metade do século XIX, foi caracterizada pelo aprimoramento das inovações ocorridas na primeira Revolução Industrial, com destaque para a difusão da máquina a vapor e das ferrovias. As empresas ferroviárias tornaram-se estruturas de negócios muito grandes, exigindo as mais avançadas inovações organizacionais e de logística para a gestão de sistemas complexos (PEREZ, 2009). Carlota Perez (2009) destaca a segunda Revolução Industrial como sendo o segundo surto/onda de desenvolvimento industrial relevante.

Uma terceira onda, destacada por Carlota Perez (2009) é caracterizada pelo uso da eletricidade, engenharia pesada e pela melhoria na manipulação do ferro e aço, o que proporcionou um amadurecimento das inovações tecnológicas e do progresso técnico, inclusive na indústria química. Importantes invenções ocorridas na época foram marcantes, com destaque para a eletricidade, motor a combustão interna, barco a vapor e o telégrafo. A moeda de um centavo, os correios, telégrafos e estradas de ferro mudaram, por exemplo, a estrutura do setor bancário de instituições locais isoladas para redes nacionais de agências locais (PEREZ, 2009).

Carlota Perez (2009) chama o quarto surto/onda de desenvolvimento, este ocorrido no início do século XX, de "era do petróleo, do automóvel e da produção em massa". O crescimento das indústrias nesse período provocou o aumento da complexidade organizacional, com destaque para as inovações organizacionais conhecidas como "fordistas-tayloristas", que provocaram alterações na estrutura da indústria. A obra de Frederick Taylor (Princípios da Administração Científica, de 1911) se destaca por demonstrar as vantagens da economia de escala e como consultor de Henry 
Ford, em seu projeto de linha de montagem, combinou os princípios de divisão do trabalho, mecanização do processo, padronização, intercâmbio de peças e administração científica racional. (TIGRE, 2005). A separação clara entre os trabalhadores de colarinho azul e branco, entre o pensamento e a execução, teve consequências que iam muito além da fábrica, e assim fez a maior produtividade alcançada com essa organização (PEREZ, 2009).

Surge um novo paradigma conhecido como "toyotista" nos anos 1970 e 1980 com importantes inovações organizacionais que provocaram o aumento da competitividade de seus produtos. A introdução de técnicas organizacionais como just-in-time, controle da qualidade total e estruturas produtivas mais horizontais e integradas em células, levaram empresas japonesas como a Toyota desafiar o oligopólio longamente estabelecido nos mercados automobilístico e de bens de consumo duráveis (TIGRE, 2005).

Considerando a importância dos paradigmas tecno-econômicos ocorridos ao longo do tempo após a primeira Revolução Industrial, o Quadro 1 apresenta de forma resumida os cinco grandes surtos/ondas de desenvolvimento e seus respectivos paradigmas técno-econômicos.

Quadro 1: Os cinco grandes surtos (ondas) de desenvolvimento e seus paradigmas técno-econômicos

\begin{tabular}{|c|c|}
\hline $\begin{array}{c}\text { Grandes ondas de } \\
\text { desenvolvimento e país } \\
\text { núcleo }\end{array}$ & Princípios de inovação "de senso comum" de paradigma tecno-econômico \\
\hline \begin{tabular}{l}
\multicolumn{1}{c}{$\mathbf{1}^{\mathbf{0}} \mathbf{1}$} \\
- A partir de 1771 \\
- Revolução Industrial \\
- Grã-Bretanha
\end{tabular} & $\begin{array}{l}\text { - Produção da fábrica } \\
\text { - Mecanização } \\
\text { - Produtividade / tempo de manutenção e economia de tempo } \\
\text { - Fluidez de movimento (máquinas à água - transporte através de canais e outras vias } \\
\text { navegáveis) } \\
\text { - Redes locais }\end{array}$ \\
\hline \begin{tabular}{l}
\multicolumn{1}{c}{$\mathbf{2}^{\mathbf{0}}$ : } \\
- A partir de 1829 \\
- Idade do vapor e estradas de \\
ferro \\
- Grã-Bretanha, se espalhando \\
para o continente e EUA
\end{tabular} & $\begin{array}{l}\text { - Economias de aglomeração / cidades industriais / mercados nacionais } \\
\text { - Centros de poder com as redes nacionais } \\
\text { - Escala de progresso } \\
\text { - Peças padrão / máquina de fazer máquinas } \\
\text { - Energia onde for necessário (vapor) } \\
\text { - Movimento interdependente (de máquinas e de meios de transporte) }\end{array}$ \\
\hline $\begin{array}{l}\qquad \mathbf{3}^{\mathbf{0}} \text { : } \\
\text { - A partir de } 1875 \\
\text { - Era do aço, eletricidade e } \\
\text { engenharia pesada } \\
\text { - EUA e Alemanha } \\
\text { ultrapassando a Grã-Bretanha }\end{array}$ & $\begin{array}{l}\text { - Estruturas gigantes (de aço) } \\
\text { - Economias de escala da planta / integração vertical } \\
\text { - Energia distribuída para a indústria (electricidade) } \\
\text { - A ciência como força produtiva } \\
\text { - Redes e impérios mundiais (incluindo cartéis) } \\
\text { - Padronização universal } \\
\text { - A contabilidade de custos para controle e eficiência } \\
\text { - Grande escala de poder de mercado mundial / "pequeno" é bem sucedido, se local }\end{array}$ \\
\hline $\begin{array}{l}\qquad \mathbf{4}^{\mathbf{0}} \text { : } \\
\text { - A partir de } 1908 \\
\text { - Era do petróleo, do } \\
\text { automóvel e da produção em } \\
\text { massa } \\
\text { - EUA, se espalhando para a } \\
\text { Europa }\end{array}$ & $\begin{array}{l}\text { - Mercados de massa, produção em massa } \\
\text { - Economias de escala (do produto e volume de mercado) / integração horizontal } \\
\text { - A normalização dos produtos } \\
\text { - A intensidade energética (base de petróleo) } \\
\text { - Os materiais sintéticos } \\
\text { - Especialização funcional / pirâmides hierárquicas } \\
\text { - Centralização / centros metropolitanos - suburbanização } \\
\text { - Poderes nacionais, acordos mundiais e confrontos }\end{array}$ \\
\hline $\begin{array}{l}\qquad \mathbf{5}^{\mathbf{0}} \text { : } \\
\text { - A partir de } 1971 \\
\text { - Era da informação e } \\
\text { telecomunicações } \\
\text { - EUA, espalhando-se para a } \\
\text { Europa e Ásia }\end{array}$ & $\begin{array}{l}\text { - Informação - intensidade (microeletrônica baseados em TIC) } \\
\text { - Integração / estruturas de redes descentralizadas } \\
\text { - Conhecimento como capital / valor intangível agregado } \\
\text { - Heterogeneidade, diversidade, adaptabilidade } \\
\text { - Segmentação dos mercados / proliferação de nichos } \\
\text { - As economias de escopo e de especialização combinada com escala } \\
\text { - Globalização / interação entre o global e o local } \\
\text { - Interior e exterior de cooperação / agrupamentos } \\
\text { - Contato imediato e ação / comunicações globais instantâneas }\end{array}$ \\
\hline
\end{tabular}

Fonte: Perez (2009). 
O quinto surto/onda de desenvolvimento mencionado por Carlota Perez (2009) é chamada de "era da informação e das telecomunicações", a partir do ano 1971. Com o surgimento da microeletrônica (microprocessadores, semicondutores), posteriormente os computadores pessoais, softwares e a Internet, as tecnologias da informação e da comunicação (TIC) proporcionaram a evolução tecnológica intensiva que vem contribuindo significativamente para a gestão da informação.

A relação entre as tecnologias "hard" (máquinas e equipamentos) e "soft" (práticas organizacionais) vem se estreitando com o uso de TIC, onde atualmente as tecnologias se encontram mais integradas diante do maior desenvolvimento do acesso à informação (TIGRE, 2006). Destaca-se que o uso de TIC possibilita, entre outros, maior acesso a informação aos seus usuários de forma rápida e com precisão, o que proporciona a integração da empresa com os demais participantes de uma cadeia de suprimentos.

Perez (2009) comenta que a prática regular no uso dessas tecnologias e no relacionamento com as novas condições do mercado contribui para o estabelecimento de novos princípios (paradigmas) de organização que provam superior ao anterior e tornam-se parte do novo senso comum para a eficiência e eficácia. As empresas e organizações não se desenvolvem no vazio, sendo estruturadas a partir de determinados contextos (ou paradigmas) que sofrem sucessivas transformações (TIGRE, 2005).

O paradigma tecno-econômico é o resultado de um processo de aprendizado coletivo complexo, articulado em um modelo dinâmico da melhor prática econômica, tecnológica e organizacional, para o período em que a revolução tecnológica específica está sendo adotada e assimilada pelo sistema econômico e social (PEREZ, 2009).

Para Tigre (2005) a ideia de "paradigma" contribui para estabelecer padrões de comportamento e identificar tecnologias-chave, no entanto, são apenas visões idealizadas de modelos organizacionais e tecnológicos dominantes em certos períodos de tempo (TIGRE, 2005). Segundo Perez (2009), cada paradigma tecno-econômico combina percepções compartilhadas, práticas compartilhadas e orientações comuns de mudança. Sua adoção facilita a obtenção da máxima eficiência e rentabilidade e sua difusão fornece um entendimento comum entre os diferentes agentes que participam da economia, dos produtores aos consumidores (PEREZ, 2009).

Em termos de estrutura, cada revolução inclui um número significativo de novos produtos inter-relacionados e tecnologias de produção, dando origem a novas e importantes indústrias (PEREZ, 2009). Os novos paradigmas se desenvolvem mais rapidamente em certos países e setores econômicos do que em outros e sua difusão é geralmente assimétrica, resultando na heterogeneidade econômica, o que reforça a necessidade de recorrer ao trabalho empírico para entender firmas e mercados (TIGRE, 2005).

Contudo, ao identificarmos os fatos históricos marcantes relacionados com a inovação, desde a primeira Revolução Industrial, é possível perceber a relação das inovações ocorridas em cada onda de desenvolvimento, e suas consequências nos aspectos produtivos e de crescimento econômico. O impacto das inovações tecnológicas e organizacionais implementadas proporcionaram a quebra de paradigmas e a sua releitura pelos estudiosos, que devem buscar adaptar a teoria à atual realidade, considerando, para isso, as atuais e possíveis futuras inovações, atentos às novas ondas de desenvolvimento e seus prováveis impactos.

O Manual de Oslo (OCDE, 2005) considera quatro tipos de inovações: (a) inovações de produto (compreendem as mudanças significativas nos produtos e serviços ou totalmente novos), (b) inovações de processo (compreendem mudanças significativas nos métodos de produção e distribuição), (c) inovações organizacionais (compreende a implementação de novos métodos organizacionais) e (d) inovações de marketing (compreende a implementação de novos métodos de marketing). 
A capacidade de lidar com a mudança inesperada vem de estruturas organizacionais flexíveis e uma cultura de mudança (GALLEGO, RUBALCABA e HIPP, 2012). Para Tigre (2006) a reorganização dos processos de negócio constitui uma importante ferramenta competitiva, pois potencializa as oportunidades abertas pelas "tecnologias duras" incorporadas em máquinas e equipamentos, onde as inovações organizacionais permitem diferenciar uma empresa de outra, aumentando a qualidade e a produtividade.

As mudanças organizacionais costumam ser mais difíceis de implementar do que as tecnológicas, pois requerem alterações em processos de negócios, nas cadeias hierárquicas de comando e controle, nas formas de acesso a informações e reformulação em rotinas e estruturas de poder cristalizadas nas empresas ao longo dos anos (TIGRE, 2006).

Os principais componentes de inovação em uma organização incluem inovação estratégica, estrutura para inovação, cultura empresarial para inovação, a inovação de fluxo de trabalho e inovação dos recursos humanos. Cada componente, por sua vez consiste em várias construções (GUAN e LIU, 2007).

A organização de uma empresa possui aspectos tácitos, a exemplo da cultura organizacional, que são construídos informalmente, onde muitas técnicas desenvolvidas com sucesso em determinadas empresas, regiões ou países, não conseguem o mesmo resultado quando aplicadas em outros contextos em função de diferenças culturais. (TIGRE, 2006).

A inovação organizacional pode servir como pré-condição para o desenvolvimento do conhecimento de uma empresa e de gestão e atuar como um facilitador para a inovação técnica (LUNDVALL e NIELSEN, 2002). Quanto mais rígida a estrutura da organização, mais difícil se torna a introdução de mudanças organizacionais. Geralmente, as empresas ou plantas industriais novas conseguem tirar proveito de uma inovação do que outras mais antigas, pois criam desde o início as condições organizacionais adequadas para incorporá-la (TIGRE, 2006).

De acordo com a Pesquisa de Inovação (PINTEC, 2011), a IO corresponde a implementação de um novo método organizacional nas práticas de negócios da empresa, na organização do seu local de trabalho ou em suas relações externas, visando melhorar o uso do conhecimento, a eficiência dos fluxos de trabalho ou a qualidade dos bens ou serviços.

A flexibilidade organizacional e a capacidade cognitiva para absorver novos conhecimentos constituem elementos críticos para a difusão de novas tecnologias úteis para solucionar problemas na introdução, otimização e adaptação de tecnologias específicas a seu ambiente de trabalho (TIGRE, 2006). Outra direção promissora para pesquisas futuras reconhece que a IO pode ser uma pré-condição necessária para a inovação tecnológica, ao invés de tratar este processo de maneira uniforme como uma resposta a forças externas, e centra-se nos processos de reforma de organização interna e de transformação que são necessárias para criar tais condições (LAM, 2005).

A relação entre as tecnologias "hard" (máquinas e equipamentos) e "soft" (práticas organizacionais) vem se estreitando com o uso de TIC. Atualmente as tecnologias se encontram mais integradas diante do maior desenvolvimento do acesso à informação (TIGRE, 2006). Para Tigre, as TIC:

Permitem aperfeiçoar as inovações organizacionais de forma a responder às crescentes pressões competitivas, a exemplo da globalização dos mercados, da necessidade de operar em tempo real, da maior orientação para as demandas específicas dos clientes, da necessidade de inovar em produtos e processos, de cumprir novas exigências éticas e ambientais, de melhorar a qualidade de produtos e serviços, de integrar a logística de suprimentos e de introduzir novas formas de organização do trabalho. (TIGRE, 2006, p. 199)

Outro aspecto que os pesquisadores de IO devem levar em consideração é o papel das forças organizacionais endógenas, tais como capacidade de aprendizagem, valores, interesses e poder na formação de evolução organizacional e mudança tecnológica. Esta é uma área onde pesquisadores 
de organização e gestão poderiam apresentar estudos, colocando uma maior ênfase na construção rigorosa pesquisa e teoria empírica (LAM, 2005). Considerados alguns aspectos da inovação e da IO, apresentam-se a seguir os procedimentos metodológicos utilizados na presente pesquisa.

\section{Procedimentos metodológicos}

Esta seção tem como objetivo apresentar os procedimentos utilizados para a realização da pesquisa. Este estudo descritivo utilizou, como base de dados, as edições de número 6 (2006-2008) e 7 (2008-2010) da Community Innovation Survey (CIS) para a obtenção dos dados das empresas da Comunidade Europeia. Foram selecionados os países que possuem o maior Produto Interno Bruto (PIB) que possuem dados disponibilizados pela CIS. Utilizou-se como base de dados as edições de 2008 e 2011 da Pesquisa de Inovação (PINTEC), realizada pelo Instituto Brasileiro de Geografia e Estatística (IBGE), para a obtenção dos dados das empresas brasileiras.

Os dados foram tabulados em planilha eletrônica, que possibilitou efetuar a análise dos dados das empresas. Os dados obtidos estão apresentados na seção composta pelos resultados do estudo, de forma descritiva e também dispostos em tabelas, onde é possível observar as quantidades dos itens apresentados, como também os percentuais.

Os dados apresentam, para cada país, o total de empresas pesquisadas, a quantidade de empresas que realizaram inovações, as empresas que realizaram somente IO e ou de marketing, somente inovação de produto, somente inovação de processo e somente Inovação Tecnológica (IT) que foram as empresas que realizaram inovação de produto e processo. Esta seleção de dados também foi apresentada considerando-se as faixas de pessoal ocupado, que compreendem as empresas que possuem de 10 a 49 empregados, de 50 a 249 empregados e com 250 ou mais empregados.

Também foi organizado um conjunto de informações dos países acerca dos objetivos considerados como muito importantes para a realização da IO. Especificamente são apresentados, considerada a faixa de pessoal ocupado, as empresas que apontaram como muito importantes os seguintes itens:

- Redução do tempo de resposta às necessidades dos clientes ou fornecedores;

- Melhorar a capacidade de desenvolver novos produtos ou processos;

- Melhoria da qualidade de bens ou serviços;

- Redução dos custos por unidade de produção;

- Melhoria da comunicação ou compartilhamento de informações.

A análise da IO realizadas pelas empresas situadas no Brasil será realizada utilizando-se dados tabulados em planilha eletrônica, apresentando, com base nas edições de 2008 e 2011 da PINTEC, os dados do total de empresas pesquisadas, total de empresas que implementaram inovações, total de empresas que realizaram inovação de produto e/ou processo, que possuem projetos incompletos e/ou abandonados e que realizaram somente IO e/ou de marketing. Também serão apresentados dados acerca dos tipos de IO realizadas, ou seja, a quantidade de empresas que realizaram os tipos de IO, quais sejam: técnicas de gestão, técnicas de gestão ambiental, organização do trabalho e relações externas. Apresentam-se a seguir os resultados do estudo.

\section{Resultados do estudo}

O objetivo desta seção é apresentar dados da IO das empresas situadas nos países da Europa selecionados, a partir de dados obtidos da CIS, e das empresas situadas no Brasil, a partir dos dados da PINTEC. 


\subsection{Resultados do estudo das empresas situadas na Comunidade Europeia}

A Tabela 1 apresenta as quantidades de empresas pesquisadas por país selecionado, quantidade de empresas que realizaram inovações e os tipos de inovações realizadas, de acordo com a Community Innovation Survey (CIS).

Considerando-se os dados da Tabela 1, comparando-se o total de empresas pesquisadas na CIS 6 com a CIS 7 nota-se que houve uma diminuição de empresas pesquisadas na Comunidade Europeia (CIS 6: 793.049 empresas; CIS 7: 730.701). Mesmo com a participação da Turquia na CIS 7, que representa mais de sessenta e quatro mil empresas, a redução da quantidade de empresas foi expressiva, principalmente na Espanha e Itália.

Identificou-se que os países com a maior relação percentual entre as empresas pesquisadas e as que realizaram inovações foram (CIS7): Alemanha: 79,3\% das empresas realizaram inovações, Itália: 56,3\%, França: 53,5\%, Turquia: 51,4\% e Espanha: 41,4\%.

Pode-se verificar a evolução da quantidade de empresas inovadoras, ao se comparar os resultados da CIS 6 com os da CIS 7. As principais reduções na quantidade de empresas inovadoras foram na França, que teve uma redução de $0,12 \%$ na quantidade de empresas inovadoras; na Alemanha teve uma redução de 1,19\%; a Itália apresentou uma redução de 4,56\% e a Espanha teve uma redução de $15,16 \%$ na quantidade de empresas inovadoras na comparação das pesquisas.

Tabela 1: Atividades de inovação por tipo - CIS 6 (2006 - 2008) e CIS 7 (2008 - 2010)

\begin{tabular}{|c|c|c|c|c|c|c|c|c|c|c|c|c|}
\hline \multirow{2}{*}{$\begin{array}{c}\text { Empresas por } \\
\text { tipo de inovação } \\
\text { Países/CIS }\end{array}$} & \multicolumn{2}{|c|}{ Total de empresas } & \multicolumn{2}{|c|}{$\begin{array}{l}\text { Empresas que } \\
\text { realizaram } \\
\text { inovações } \\
\text { (incluindo } \\
\text { empresas que } \\
\text { tiveram atividades } \\
\text { de inovação } \\
\text { abandonadas e/ou } \\
\text { suspensas) }\end{array}$} & \multicolumn{2}{|c|}{$\begin{array}{c}\text { Somente inovações } \\
\text { organizacionais } \\
\text { e/ou de marketing }\end{array}$} & \multicolumn{2}{|c|}{$\begin{array}{l}\text { Somente inovações } \\
\text { de produto }\end{array}$} & \multicolumn{2}{|c|}{$\begin{array}{l}\text { Somente inovações } \\
\text { de processo }\end{array}$} & \multicolumn{2}{|c|}{$\begin{array}{c}\text { Somente inovações } \\
\text { de produto e } \\
\text { processo }\end{array}$} \\
\hline & CIS 6 & CIS 7 & CIS 6 & CIS 7 & CIS 6 & CIS 7 & CIS 6 & CIS 7 & CIS 6 & CIS 7 & CIS 6 & CIS 7 \\
\hline $\begin{array}{l}\text { European Union } \\
\text { ( } 27 \text { countries) }\end{array}$ & 793.049 & 730.701 & 408.964 & 386.833 & $:$ & 102.027 & $:$ & 80.775 & $:$ & 62.433 & $:$ & 110.563 \\
\hline Czech Republic & 23.566 & 20.553 & 13.196 & 10.623 & 3.941 & 3.479 & 1.366 & 1.944 & 2.851 & 1.688 & 4.398 & 3.016 \\
\hline Germany & 127.583 & 127.073 & 101.953 & 100.743 & 20.611 & 19.147 & 23.871 & 26.248 & 17.440 & 10.964 & 28.808 & 26.513 \\
\hline Spain & 84.537 & 75.468 & 36.809 & 31.227 & 9.859 & 9.182 & 3.824 & 3.259 & 11.981 & 9.611 & 8.246 & 7.053 \\
\hline France & 73.825 & 69.194 & 37.046 & 37.002 & 11.174 & 13.254 & 5.949 & 6.053 & 7.594 & 5.867 & 11.313 & 10.324 \\
\hline Italy & 131.368 & 118.567 & 69.941 & 66.751 & 17.225 & 18.829 & 9.311 & 11.892 & 13.298 & 11.004 & 26.727 & 22.191 \\
\hline Poland & 51.162 & 50.625 & 14.295 & 14.247 & 4.165 & 6.051 & 1.978 & 1.847 & 2.902 & 2.514 & 4.968 & 3.400 \\
\hline Portugal & 20.627 & 20.163 & 11.925 & 12.167 & 1.585 & 2.816 & 1.381 & 1.174 & 3.050 & 3.080 & 5.582 & 4.825 \\
\hline Romania & 29.979 & 26.330 & 9.986 & 8.116 & 4.079 & 4.353 & 710 & 635 & 1.965 & 955 & 3.073 & 2.041 \\
\hline United Kingdom & 82.828 & 72.201 & 37.789 & 31.981 & $:$ & 8.401 & $:$ & 11.040 & $:$ & 2.596 & $:$ & 7.960 \\
\hline Turkey & $:$ & 64.234 & & 32.990 & $:$ & 10.406 & $:$ & 3.692 & $:$ & 5.674 & $:$ & 11.949 \\
\hline
\end{tabular}

Fonte: Adaptado da CIS 6 e CIS 7.

Comparando o total de empresas pesquisadas na CIS 6 com a CIS 7 nota-se que houve uma diminuição de empresas pesquisadas na Comunidade Europeia (CIS 6: 793.049 empresas; CIS 7: 730.701). Mesmo com a participação da Turquia na CIS 7, que representa mais de sessenta mil empresas, a redução da quantidade de empresas foi expressiva principalmente na Espanha, Itália e Reino Unido.

Uma análise que pode ser realizada é a identificação dos países com a maior quantidade de empresas para verificar a relação empresas pesquisadas/inovadoras. Considerando para análise os países com mais de cinquenta mil empresas pesquisadas na CIS 7, identifica-se os países com a maior relação percentual entre as empresas pesquisadas e as que realizaram inovações: Alemanha $79,3 \%$ das empresas realizaram inovações, Itália $(56,3 \%)$, França $(53,5 \%)$, Turquia $(51,4 \%)$, Reino Unido (44,3\%) e Espanha (41,4\%). 
Pode-se verificar a evolução da quantidade de empresas inovadoras, ao compararmos os resultados da CIS 6 com os da CIS 7. A França teve uma redução de 0,12\% na quantidade de empresas inovadoras; a Alemanha teve uma redução de 1,19\%; a Itália apresentou uma redução de 4,56\%; a Espanha teve uma redução de $15,16 \%$ e o Reino Unido teve uma redução de $15,37 \%$ na quantidade de empresas inovadoras na comparação das pesquisas.

Considerando os países que possuem a maior quantidade de empresas pesquisadas e que realizaram inovações, de acordo com os dados da CIS 7, pode-se identificar o percentual de empresas que realizaram somente IO e/ou de Marketing, como segue: França: 35,8\% das empresas realizaram somente IO e/ou de Marketing, Turquia (31,5\%), Espanha (29,4\%), Itália (28,2\%), Reino Unido (26,3\%) e Alemanha (19,0\%).

Percebe-se que os países da Comunidade Europeia que possuem a maior quantidade de empresas pesquisadas e também a maior quantidade de empresas que realizaram inovações, foram os que realizaram menos IO em relação aos demais, com destaque para a Alemanha $(79,3 \%$ das empresas realizaram inovações, porém $19 \%$ das empresas inovadoras realizaram somente IO e de Marketing). Por outro lado, tomando como exemplo a Alemanha, seu alto percentual de empresas que realizam inovações e o baixo percentual de empresas que realizam somente IO ou somente inovações de produto ou somente de processo, mostra que essas empresas realizam não só um tipo de inovação, mas se dedicam à realização de inovações de produto, processo e IO e de Marketing.

Ao considerarmos as informações da CIS 6 (2006-2008) e CIS 7 (2008-2010) sobre as inovações das empresas dos países da Comunidade Europeia, por tamanho de empresa, considerando para isso a quantidade de empregados por empresa, a Tabela 2 apresenta os dados das empresas europeias por país da Comunidade Europeia por faixa/tamanho de empresa.

Tabela 2: Atividades de inovação por tipo e porte (10 a 49 empregados) - CIS 6 e CIS 7

\begin{tabular}{|c|c|c|c|c|c|c|c|c|c|c|c|c|}
\hline \multirow[t]{2}{*}{$\begin{array}{c}\text { Empresas por } \\
\text { tipo de inovação } \\
10 \text { a } 49 \\
\text { empregados }\end{array}$} & \multicolumn{2}{|c|}{ Total de empresas } & \multicolumn{2}{|c|}{$\begin{array}{c}\text { Empresas que } \\
\text { realizaram } \\
\text { inovações } \\
\text { (incluindo } \\
\text { empresas que } \\
\text { tiveram atividades } \\
\text { de inovação } \\
\text { abandonadas e/ou } \\
\text { suspensas) }\end{array}$} & \multicolumn{2}{|c|}{$\begin{array}{c}\text { Somente inovações } \\
\text { organizacionais } \\
\text { e/ou de marketing }\end{array}$} & \multicolumn{2}{|c|}{$\begin{array}{c}\text { Somente inovações } \\
\text { de produto }\end{array}$} & \multicolumn{2}{|c|}{$\begin{array}{l}\text { Somente } \\
\text { inovações de } \\
\text { processo }\end{array}$} & \multicolumn{2}{|c|}{$\begin{array}{l}\text { Somente inovações } \\
\text { de produto e } \\
\text { processo }\end{array}$} \\
\hline & CIS 6 & CIS 7 & CIS 6 & CIS 7 & CIS 6 & CIS 7 & CIS 6 & CIS 7 & CIS 6 & CIS 7 & CIS 6 & CIS 7 \\
\hline $\begin{array}{l}\text { European Union } \\
\text { ( } 27 \text { countries) }\end{array}$ & 630.140 & 578.511 & 300.854 & 284.748 & : & 83.158 & & 60.062 & & 45.663 & & 71.358 \\
\hline Czech Republic & 17.575 & 15.493 & 9.185 & 7.228 & 3.115 & 2.650 & 855 & 1.340 & 2.170 & 1.172 & 2.621 & 1.689 \\
\hline Germany & 94.815 & 94.808 & 73.694 & 72.530 & 16.764 & 15.677 & 18.702 & 19.319 & 12.843 & 7.299 & 16.424 & 15.651 \\
\hline Spain & 71.185 & 63.465 & 28.536 & 23.770 & 8.558 & 8.099 & 2.820 & 2.451 & 9.457 & 7.478 & 5.445 & 4.108 \\
\hline France & 58.399 & 54.502 & 26.297 & 26.507 & 8.998 & 10.711 & 3.954 & 3.914 & 5.602 & 4.340 & 7.036 & 6.472 \\
\hline Italy & 114.119 & 102.509 & 57.317 & 55.204 & 15.065 & 16.493 & 7.826 & 10.055 & 11.162 & 9.259 & 20.323 & 16.988 \\
\hline Poland & 38.347 & 37.844 & 8.592 & 8.528 & 3.097 & 4.605 & 1.096 & 976 & 1.692 & 1.298 & 2.539 & 1.368 \\
\hline Portugal & 16.804 & 16.565 & 9.182 & 9.595 & 1.336 & 2.484 & 1.071 & 911 & 2.463 & 2.496 & 4.067 & 3.491 \\
\hline Romania & 22.773 & 20.379 & 6.797 & 5.613 & 3.010 & 3.227 & 449 & 394 & 1.324 & 638 & 1.907 & 1.253 \\
\hline United Kingdom & 65.417 & 56.713 & 28.111 & 24.150 & r & 6.551 & & 8.445 & 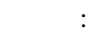 & 1.861 & : & 5.802 \\
\hline Turkey & & 52.735 & & 26.020 & & 8.731 & & 2.873 & & 4.316 & & 9.120 \\
\hline
\end{tabular}

Fonte: Adaptado da CIS 6 e CIS 7.

Do total de empresas da Comunidade Europeia pesquisadas na CIS 7, pode-se observar que 79,2\% dessas empresas possuem entre 10 e 49 empregados; 49,2\% das empresas pesquisadas realizaram inovações; $29,2 \%$ das empresas inovadoras realizaram somente IO e de Marketing. Na faixa de 10 a 49 empregados, na CIS 7, destacam-se: Alemanha: 76,5\% das empresas realizaram inovações, Portugal (57,9\%), Itália (53,9\%), Turquia (49,3\%), França (48,6\%), Reino Unido $(42,6 \%)$ e Espanha $(37,5 \%)$.

Portanto, as empresas da Comunidade Europeia participantes da CIS 7 que possuem entre 10 e 49 empregados são as que formam o maior grupo de empresas por tamanho (correspondendo a 
$79,2 \%$ do total de empresas pesquisadas), mas formam o grupo das empresas que são percentualmente menos inovadoras (49,2\% das empresas desse grupo realizaram inovações).

Considerando os países que possuem a maior quantidade de empresas pesquisadas e que realizaram inovações, de acordo com os dados da CIS 7, na faixa de pessoal ocupado entre 10 e 49 empregados, pode-se identificar o percentual de empresas que realizaram somente IO e/ou de Marketing, como segue: França 40,4\% das empresas realizaram somente IO e/ou de Marketing, Espanha (34,1\%), Turquia (33,6\%), Itália (29,9\%), Reino Unido (27,1\%) e Alemanha: 21,6\%.

A Tabela 3 apresenta os dados das atividades de inovação por tipo e tamanho/faixa de pessoal ocupado entre 50 e 249 empregados.

Tabela 3: Atividades de inovação por tipo e porte (50 a 249 empregados) - CIS 6 e CIS 7

\begin{tabular}{|c|c|c|c|c|c|c|c|c|c|c|c|c|}
\hline \multirow[t]{2}{*}{$\begin{array}{c}\text { Empresas por } \\
\text { tipo de inovação } \\
50 \text { a } 249 \\
\text { empregados }\end{array}$} & \multicolumn{2}{|c|}{ Total de empresas } & \multicolumn{2}{|c|}{$\begin{array}{c}\text { Empresas que } \\
\text { realizaram } \\
\text { inovações } \\
\text { (incluindo } \\
\text { empresas que } \\
\text { tiveram atividades } \\
\text { de inovação } \\
\text { abandonadas e/ou } \\
\text { suspensas) }\end{array}$} & \multicolumn{2}{|c|}{$\begin{array}{c}\text { Somente inovações } \\
\text { organizacionais } \\
\text { e/ou de marketing }\end{array}$} & \multicolumn{2}{|c|}{$\begin{array}{c}\text { Somente inovações } \\
\text { de produto }\end{array}$} & \multicolumn{2}{|c|}{$\begin{array}{c}\text { Somente } \\
\text { inovações de } \\
\text { processo }\end{array}$} & \multicolumn{2}{|c|}{$\begin{array}{c}\text { Somente inovações } \\
\text { de produto e } \\
\text { processo }\end{array}$} \\
\hline & CIS 6 & CIS 7 & CIS 6 & CIS 7 & CIS 6 & CIS 7 & CIS 6 & CIS 7 & CIS 6 & CIS 7 & CIS 6 & CIS 7 \\
\hline $\begin{array}{l}\text { European Union } \\
\text { ( } 27 \text { countries })\end{array}$ & 133.911 & 125.248 & 85.248 & 80.928 & : & 16.171 & : & : & $:$ & $:$ & & 28.068 \\
\hline Czech Republic & 4.799 & 3.978 & 3.048 & 2.545 & 704 & 694 & 411 & 483 & 548 & 394 & 1.194 & 880 \\
\hline Germany & 26.478 & 26.198 & 22.307 & 22.526 & 3.390 & 2.914 & 4.260 & 5.825 & 3.802 & 3.131 & 8.997 & 7.583 \\
\hline Spain & 11.392 & 10.227 & 6.738 & 6.010 & 1.197 & 981 & 832 & 685 & 2.176 & 1.803 & 1.981 & 2.121 \\
\hline France & 12.216 & 11.718 & 8.124 & 7.997 & 1.812 & 2.150 & 1.541 & 1.671 & 1.635 & 1.220 & 2.892 & 2.616 \\
\hline Italy & 14.774 & 13.698 & 10.597 & 9.570 & 1.960 & 2.032 & 1.239 & 1.556 & 1.803 & 1.468 & 5.220 & 4.136 \\
\hline Poland & 10.643 & 10.632 & 4.254 & 4.262 & 894 & 1.226 & 719 & 706 & 896 & 898 & 1.655 & 1.308 \\
\hline Portugal & 3.344 & 3.155 & 2.314 & 2.181 & 221 & 305 & 282 & 238 & 511 & 534 & 1.223 & 1.054 \\
\hline Romania & 5.846 & 4.836 & 2.388 & 1.874 & 868 & 938 & 205 & 170 & 487 & 216 & 788 & 526 \\
\hline United Kingdom & 14.141 & 12.582 & 7.769 & 6.466 & : & 1.621 & $:$ & 2.204 & $:$ & 576 & $:$ & 1.640 \\
\hline Turkey & : & 9.637 & $:$ & 5.672 & : & 1.417 & $:$ & 692 & $:$ & 1.139 & $:$ & 2.162 \\
\hline
\end{tabular}

Fonte: Adaptado da CIS 6 e CIS 7.

Do total de empresas da Comunidade Europeia pesquisadas na CIS 7, pode-se observar que $17,1 \%$ dessas empresas possuem entre 50 e 249 empregados; 64,6\% dessas empresas realizaram inovações e $20,0 \%$ das empresas que realizaram inovações realizaram somente IO e de Marketing. Das empresas pesquisadas na faixa de 50 a 249 empregados na CIS 7, destacam-se: Alemanha $86,0 \%$ das empresas realizaram inovações, Itália $(69,9 \%)$, Portugal $(69,1 \%)$, França (68,2\%), Turquia (58,9\%), Espanha (58,8\%) e Reino Unido (51,4\%).

Foi possível identificar o percentual de empresas que realizaram somente IO e/ou de Marketing de acordo com os dados da CIS 7, na faixa de pessoal ocupado entre 50 e 249 empregados, como segue: França 26,9\% das empresas realizaram somente IO e/ou de Marketing, Reino Unido (25,1\%), Turquia (25,0\%), Itália (21,2\%), Espanha (16,3\%) e Alemanha (12,9\%).

A Tabela 4 apresenta os dados das atividades de inovação por tipo e tamanho/faixa de pessoal ocupado das empresas que possuem mais de 250 empregados. Considerando o total de empresas da Comunidade Europeia pesquisadas na CIS 7, pode-se observar que 3,7\% dessas empresas possuem mais de 250 empregados e 78,5\% dessas empresas realizaram inovações. Não foi possível identificar o total de empresas realizaram somente IO e de Marketing. Das empresas pesquisadas que possuem mais de 250 empregados na CIS 7, destacam-se: Alemanha: 93,7\% das empresas realizaram inovações, Portugal (88,3\%), França (84,0\%), Itália (83,8\%), Espanha (81,5\%), Turquia $(69,7 \%)$ e Reino Unido $(47,0 \%)$.

Portanto, as empresas da Comunidade Europeia participantes da CIS 7 que possuem mais de 250 empregados são as que possuem o menor número (3,7\% do total de empresas pesquisadas), mas 
forma o grupo das empresas que são percentualmente mais inovadoras (78,5\% das empresas desse grupo realizaram inovações).

De acordo com os dados da CIS 7, das empresas na faixa de pessoal ocupado acima de 250 empregados, pode-se identificar o percentual de empresas que realizaram somente IO e/ou de Marketing, como segue: Turquia 19,8\% das empresas realizaram somente IO e/ou de Marketing, Reino Unido (16,8\%), França (15,8\%), Itália (15,4\%), Alemanha (9,8\%) e Espanha: 7,0\%.

Tabela 4: Atividades de inovação por tipo e porte (250 ou mais empregados) - CIS 6 e CIS 7

\begin{tabular}{|c|c|c|c|c|c|c|c|c|c|c|c|c|}
\hline \multirow[t]{2}{*}{$\begin{array}{c}\text { Empresas por tipo } \\
\text { de inovação com } \\
250 \text { ou mais } \\
\text { empregados }\end{array}$} & \multicolumn{2}{|c|}{ Total de empresas } & \multicolumn{2}{|c|}{$\begin{array}{c}\text { Empresas que } \\
\text { realizaram } \\
\text { inovações } \\
\text { (incluindo } \\
\text { empresas que } \\
\text { tiveram atividades } \\
\text { de inovação } \\
\text { abandonadas e/ou } \\
\text { suspensas) } \\
\end{array}$} & \multicolumn{2}{|c|}{$\begin{array}{c}\text { Somente } \\
\text { inovações } \\
\text { organizacionais } \\
\text { e/ou de marketing }\end{array}$} & \multicolumn{2}{|c|}{$\begin{array}{l}\text { Somente } \\
\text { inovações de } \\
\text { produto }\end{array}$} & \multicolumn{2}{|c|}{$\begin{array}{c}\text { Somente } \\
\text { inovações de } \\
\text { processo }\end{array}$} & \multicolumn{2}{|c|}{$\begin{array}{c}\text { Somente } \\
\text { inovações de } \\
\text { produto e processo }\end{array}$} \\
\hline & CIS 6 & CIS 7 & CIS 6 & CIS 7 & CIS 6 & CIS 7 & CIS 6 & CIS 7 & CIS 6 & CIS 7 & CIS 6 & CIS 7 \\
\hline $\begin{array}{l}\text { European Union } \\
\text { ( } 27 \text { countries) }\end{array}$ & 28.997 & 26.940 & 22.861 & 21.157 & $:$ & $:$ & $:$ & $:$ & $:$ & $:$ & $:$ & 11.134 \\
\hline Czech Republic & 1.193 & 1.081 & 963 & 850 & 122 & 135 & 100 & 122 & 133 & 122 & 583 & 447 \\
\hline Germany & 6.290 & 6.067 & 5.952 & 5.687 & 458 & 556 & 909 & 1.104 & 795 & 534 & 3.387 & 3.279 \\
\hline Spain & 1.961 & 1.776 & 1.535 & 1.447 & 103 & 102 & 172 & 124 & 348 & 330 & 819 & 824 \\
\hline France & 3.209 & 2.974 & 2.624 & 2.498 & 364 & 394 & 454 & 467 & 358 & 306 & 1.385 & 1.235 \\
\hline Italy & 2.475 & 2.360 & 2.027 & 1.977 & 199 & 304 & 246 & 280 & 334 & 277 & 1.185 & 1.067 \\
\hline Poland & 2.172 & 2.150 & 1.449 & 1.457 & 174 & 219 & 163 & 165 & 314 & 317 & 774 & 723 \\
\hline Portugal & 479 & 443 & 429 & 391 & 28 & 27 & 28 & 26 & 76 & 50 & 292 & 279 \\
\hline Romania & 1.360 & 1.115 & 801 & 629 & 201 & 188 & 56 & 71 & 154 & 101 & 378 & 262 \\
\hline United Kingdom & 3.271 & 2.905 & 1.908 & 1.365 & $:$ & 230 & 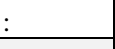 & 390 & $:$ & 159 & $:$ & 518 \\
\hline Turkey & & 1.862 & $:$ & 1.298 & & 257 & $:$ & 127 & $:$ & 218 & : & 667 \\
\hline
\end{tabular}

Fonte: Adaptado da CIS 6 e CIS 7.

O Manual de Oslo considerou, como objetivos importantes para a IO, os seguintes itens:

- Redução do tempo de resposta às necessidades dos clientes ou fornecedores;

- Melhorar a capacidade de desenvolver novos produtos ou processos;

- Melhoria da qualidade de bens ou serviços;

- Redução dos custos por unidade de produção;

- Melhoria da comunicação ou compartilhamento de informações.

Considerando os países com a maior quantidade de empresas pesquisadas pela CIS 7, a Tabela 5 apresenta a quantidade de empresas que assinalaram os respectivos objetivos muito importantes para a IO (com exceção da Alemanha e Reino Unido, pois seus dados não estavam disponibilizados).

Em relação a quantidade de empresas que realizaram inovações, pode-se identificar o percentual de empresas que consideram determinado objetivo como muito importante. As "empresas para as quais a redução do tempo de resposta às necessidades dos clientes ou fornecedores é um objetivo muito importante", merecem destaque os seguintes países: Portugal $(37,1 \%)$, Romênia $(33,7 \%)$ e França $(33,4 \%)$.

As "empresas para que melhorar a capacidade de desenvolver novos produtos ou processos é um objetivo muito importante" destacam-se os seguintes países: Portugal (25,3\%), Romênia $(22,8 \%)$ e Itália $(22,2 \%)$. 
Tabela 5: Objetivos muito importantes para a IO - total de empresas - CIS 7

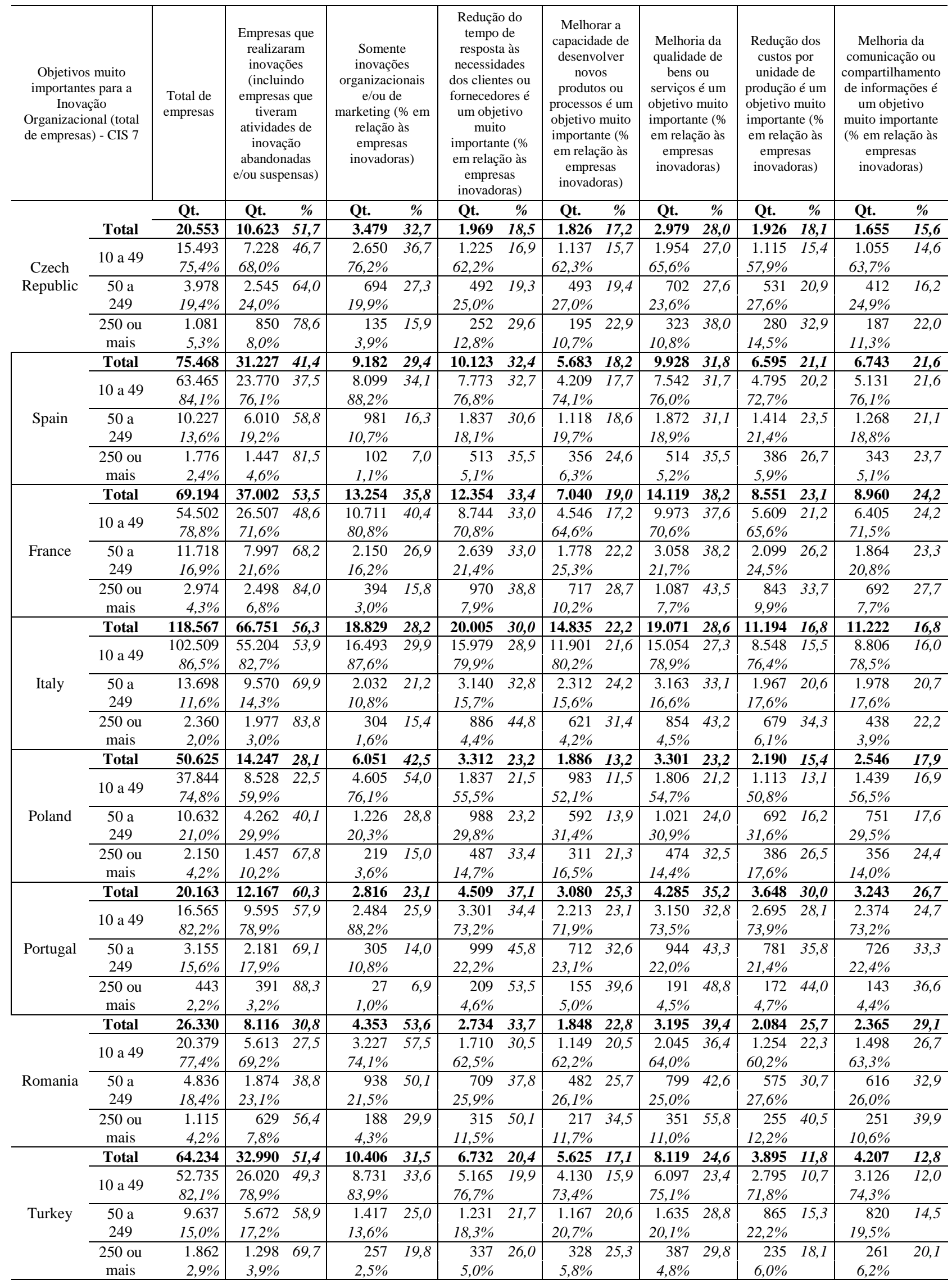

Fonte: Dados da pesquisa. 
As "Empresas para as quais a melhoria da qualidade de bens ou serviços é um objetivo muito importante" destacam-se nos seguintes países: Romênia $(39,4 \%)$, França $(38,2 \%)$ e Portugal $(35,2 \%)$.

As "Empresas para as quais a redução dos custos por unidade de produção é um objetivo muito importante" destacam-se nos seguintes países: Portugal $(30,0 \%)$, Romênia $(25,7 \%)$ e França $(23,1 \%)$.

As "Empresas para as quais a melhoria da comunicação ou compartilhamento de informações é um objetivo muito importante" destacam-se nos seguintes países: Romênia $(29,1 \%)$, Portugal $(26,7 \%)$ e França $(24,2 \%)$.

Para que seja possível a análise dos objetivos muito importantes para a IO nas empresas da Comunidade Europeia pesquisadas, será apresentada a análise dos objetivos mencionados como muito importantes para a IO, por faixa de pessoal ocupado. A análise dos dados por faixa de pessoal ocupado permitirá identificar a importância dada pelas empresas dos países pesquisados, em relação aos objetivos que elas consideraram como importantes para a realização de IO, e compará-las entre as faixas de pessoal ocupado.

Ao considerarmos a quantidade de empresas que realizaram inovações, é possível identificar o percentual de empresas que consideram determinado objetivo como muito importante, por faixa de pessoal ocupado de 10 a 49 empregados. As "empresas para as quais a redução do tempo de resposta às necessidades dos clientes ou fornecedores é um objetivo muito importante" merecem destaque os seguintes países: Portugal (34,4\%), França (33,0\%) e Espanha (32,7\%).

As "empresas para que melhorar a capacidade de desenvolver novos produtos ou processos é um objetivo muito importante" destacam-se os seguintes países: Portugal $(23,1 \%)$, Itália $(21,6 \%)$ e Romênia (20,5\%).

As "Empresas para as quais a melhoria da qualidade de bens ou serviços é um objetivo muito importante" destacam-se nos seguintes países: França (37,6\%), Romênia $(36,4 \%)$ e Portugal $(32,8 \%)$.

As "Empresas para as quais a redução dos custos por unidade de produção é um objetivo muito importante" destacam-se nos seguintes países: Portugal $(28,1 \%)$, Romênia $(22,3 \%)$ e França $(21,2 \%)$.

As "Empresas para as quais a melhoria da comunicação ou compartilhamento de informações é um objetivo muito importante" destacam-se nos seguintes países: Romênia $(26,7 \%)$, Portugal $(24,7 \%)$ e França $(24,2 \%)$.

A análise a seguir se refere às empresas que consideram determinado objetivo como muito importante para a IO, por faixa de pessoal ocupado de 50 a 249 empregados. Ao considerarmos a quantidade de empresas que realizaram inovações, é possível identificar o percentual de empresas que apontaram esses objetivos. As "empresas para as quais a redução do tempo de resposta às necessidades dos clientes ou fornecedores é um objetivo muito importante", merecem destaque os seguintes países: Portugal (45,8\%), Romênia (37,8\%) e França (33,0\%).

As "empresas para que melhorar a capacidade de desenvolver novos produtos ou processos é um objetivo muito importante" destacam-se os seguintes países: Portugal (32,6\%), Romênia $(25,7 \%)$ e Itália $(24,2 \%)$.

As "Empresas para as quais a melhoria da qualidade de bens ou serviços é um objetivo muito importante" destacam-se nos seguintes países: Portugal (43,3\%), Romênia $(42,6 \%)$ e França $(38,2 \%)$.

As "Empresas para as quais a redução dos custos por unidade de produção é um objetivo muito importante" destacam-se nos seguintes países: Portugal $(35,8 \%)$, Romênia $(30,7 \%)$ e França $(26,2 \%)$. 
As "Empresas para as quais a melhoria da comunicação ou compartilhamento de informações é um objetivo muito importante" destacam-se nos seguintes países: Portugal (33,3\%), Romênia (32,9\%) e França (23,3\%).

Se considerarmos a quantidade de empresas que realizaram inovações, é possível identificar o percentual de empresas que consideram determinado objetivo como muito importante, por faixa de pessoal ocupado de empresas com mais de 250 empregados. As "empresas para as quais a redução do tempo de resposta às necessidades dos clientes ou fornecedores é um objetivo muito importante", merecem destaque os seguintes países: Portugal $(53,5 \%)$, Romênia $(50,1 \%)$ e Itália $(44,8 \%)$.

As "empresas para que melhorar a capacidade de desenvolver novos produtos ou processos é um objetivo muito importante" destacam-se os seguintes países: Portugal (39,6\%), Romênia $(34,5 \%)$ e Itália $(31,4 \%)$.

As "Empresas para as quais a melhoria da qualidade de bens ou serviços é um objetivo muito importante" destacam-se nos seguintes países: Romênia $(55,8 \%)$, Portugal $(48,8 \%)$ e França $(43,5 \%)$.

As "Empresas para as quais a redução dos custos por unidade de produção é um objetivo muito importante" destacam-se nos seguintes países: Portugal $(44,0 \%)$, Romênia $(40,5 \%)$ e Itália $(34,3 \%)$.

As "Empresas para as quais a melhoria da comunicação ou compartilhamento de informações é um objetivo muito importante" destacam-se nos seguintes países: Romênia (39,9\%), Portugal $(36,6 \%)$ e França $(27,7 \%)$.

\subsection{Resultados da IO nas empresas situadas no Brasil}

Para compreender o comportamento das empresas situadas no Brasil, serão apresentados a seguir, alguns dados das IO das empresas pesquisadas. Com base na Pesquisa de Inovação (PINTEC), edições de 2008 e 2011, realizada pelo Instituto Brasileiro de Geografia e Estatística (IBGE). É importante ressaltar que a PINTEC dos anos de 2003 e de 2005 apresentam os resultados de apenas uma questão envolvendo mudanças estratégicas e organizacionais por parte das empresas. Tais mudanças eram especificas para mudanças na estratégia corporativa e/ou na implementação de técnicas avançadas de gestão (da produção, da informação, ambiental).

A partir da PINTEC 2008, a inovação pode ser analisada segundo um conceito mais amplo, que incorpora inovações não tecnológicas. Assim, considera-se que a implementação de novidades organizacionais pode melhorar o uso do conhecimento, a eficiência dos fluxos de trabalho ou a qualidade dos bens ou serviços para as empresas. A Tabela 6 apresenta os dados das atividades de inovação por setor, de acordo com a PINTEC de 2008 e 2011.

Tabela 6: Atividades de inovação por setor - PINTEC 2008 e 2011

\begin{tabular}{|c|c|c|c|c|c|c|c|c|c|c|c|c|c|c|}
\hline \multirow{4}{*}{$\begin{array}{c}\text { Atividades da } \\
\text { indústria PINTEC } \\
2008 \text { e } 2011\end{array}$} & \multicolumn{14}{|c|}{ Empresas } \\
\hline & \multicolumn{14}{|c|}{ Que implementaram } \\
\hline & \multicolumn{2}{|c|}{ Total } & \multicolumn{4}{|c|}{ Inovação de produto e/ou processo } & \multicolumn{4}{|c|}{$\begin{array}{c}\text { Apenas projetos incompletos } \\
\text { e/ou abandonados }\end{array}$} & \multicolumn{4}{|c|}{ Apenas IO e/ou de marketing } \\
\hline & 2008 & 2011 & 2008 & $\%$ & 2011 & $\%$ & 2008 & $\%$ & 2011 & $\%$ & 2008 & $\%$ & 2011 & $\%$ \\
\hline \multirow{2}{*}{ Total } & 106862 & 128699 & 41262 & $38.6 \%$ & 45950 & $35.7 \%$ & 2743 & $2.6 \%$ & 3158 & $2.5 \%$ & 37172 & $34.8 \%$ & 44955 & $34.9 \%$ \\
\hline & $100.0 \%$ & $100.0 \%$ & $100.0 \%$ & & $100.0 \%$ & & $100.0 \%$ & & $100.0 \%$ & & $100.0 \%$ & & $100.0 \%$ & \\
\hline \multirow{2}{*}{$\begin{array}{l}\text { Indústria de } \\
\text { transformação }\end{array}$} & 98420 & 114212 & 37808 & $38.4 \%$ & 41012 & $35.9 \%$ & 2549 & $2.6 \%$ & 2615 & $2.3 \%$ & 34419 & $35.0 \%$ & 40166 & $35.2 \%$ \\
\hline & $92.1 \%$ & $88.7 \%$ & $91.6 \%$ & & $89.3 \%$ & & $92.9 \%$ & & $82.8 \%$ & & $92.6 \%$ & & $89.3 \%$ & \\
\hline
\end{tabular}

Fonte: Adaptado de IBGE, Diretoria de Pesquisas, Coordenação de Indústria, Pesquisa de Inovação.

Observando-se em termos relativos, a edição de 2011 da PINTEC, a indústria de transformação corresponde a 88,7\% do total de empresas pesquisadas, e na edição de 2008 este 
percentual superior, alcançando $92,1 \%$ das empresas pesquisadas. Nota-se, portanto, a diminuição, em termos relativos, do percentual de empresas da indústria de transformação participante da pesquisa. Em termos absolutos, a quantidade de indústrias de transformação foi superior na edição da PINTEC de 2011, comparando-se com a edição de 2008.

Comparando-se as edições de 2008 e 2011 da PINTEC, acerca das indústrias de transformação que implementaram inovação de produto e/ou processo, nota-se que houve diminuição de 2,5 pontos percentuais, porém, houve um aumento na quantidade de empresas deste segmento. Observou-se também que houve um aumento, tanto em termos absolutos como relativos, das empresas que realizaram somente $\mathrm{IO}$ e/ou de marketing.

A Pesquisa de Inovação realizada pelo IBGE destaca quatro tipos de IO: Relações com outras empresas e instituições; Métodos de organização do trabalho; Técnicas de gestão ambiental; e Técnicas de gestão. A Tabela 7 apresenta o total de empresas que implementaram determinado tipo de IO, de acordo com a PINTEC 2011.

Tabela 7: Empresas que implementaram IT e IO: total e por atividade realizada - PINTEC 2011

\begin{tabular}{|c|c|c|c|c|c|c|c|c|c|c|c|}
\hline \multirow{5}{*}{$\begin{array}{c}\text { Atividades da } \\
\text { indústria PINTEC } \\
2011\end{array}$} & \multicolumn{11}{|c|}{ Empresas } \\
\hline & \multirow{4}{*}{ Total } & \multicolumn{10}{|c|}{ Que implementaram inovações } \\
\hline & & \multirow{2}{*}{\multicolumn{2}{|c|}{ Total }} & \multicolumn{8}{|c|}{$\mathrm{IO}$} \\
\hline & & & & \multicolumn{2}{|c|}{$\begin{array}{l}\text { Técnicas de } \\
\text { gestão }\end{array}$} & \multicolumn{2}{|c|}{$\begin{array}{c}\text { Técnicas de gestão } \\
\text { ambiental }\end{array}$} & \multicolumn{2}{|c|}{$\begin{array}{l}\text { Organização do } \\
\text { trabalho }\end{array}$} & \multicolumn{2}{|c|}{ Relações externas } \\
\hline & & Qt. & $\%$ & Qt. & $\%$ & Qt. & $\%$ & Qt. & $\%$ & Qt. & $\%$ \\
\hline \multirow{2}{*}{ Total } & 128699 & 45950 & $35.7 \%$ & 26402 & $20.5 \%$ & 17236 & $13.4 \%$ & 23913 & $18.6 \%$ & 11894 & $9.2 \%$ \\
\hline & $100.0 \%$ & $100.0 \%$ & & $100.0 \%$ & & $100.0 \%$ & & $100.0 \%$ & & $100.0 \%$ & \\
\hline \multirow{2}{*}{$\begin{array}{l}\text { Indústrias de } \\
\text { transformação }\end{array}$} & 114212 & 41012 & $35.9 \%$ & 23194 & $20.3 \%$ & 15841 & $13.9 \%$ & 20836 & $18.2 \%$ & 10111 & $8.9 \%$ \\
\hline & $88.7 \%$ & $89.3 \%$ & & $87.8 \%$ & & $91.9 \%$ & & $87.1 \%$ & & $85.0 \%$ & \\
\hline
\end{tabular}

Fonte: IBGE, Diretoria de Pesquisas, Coordenação de Indústria, Pesquisa de Inovação 2011.

De acordo com os dados da Tabela 7, verifica-se que a quantidade de empresas que implementaram IO apontaram especificamente as "inovações em técnicas de gestão" e "inovações na organização do trabalho" como os tipos de IO mais implementadas. Do total de empresas pesquisadas, 20,5\% apontaram que implementaram "inovações em técnicas de gestão", 13,4\% apontaram que implementaram "inovações em técnicas de gestão ambiental", 18,6\% apontaram que implementaram "inovações na organização do trabalho" e 9,2\% apontaram que implementaram "inovações em relações externas". Observou-se também que os percentuais dos itens analisados, referentes ao setor da indústria de transformação, foram próximos do total de empresas, por se tratar do setor que possuiu a maior quantidade de empresas.

A análise anteriormente realizada foi efetuada com base nas empresas que realizaram IT e que realizaram também IO. A análise da IO das empresas que não realizaram IT torna-se importante e será realizada considerando os dados da Tabela 8.

Tabela 8: Empresas somente implementaram IO: total e por atividade realizada - Brasil - PINTEC 2011

\begin{tabular}{|c|c|c|c|c|c|c|c|c|c|c|c|}
\hline \multirow{5}{*}{$\begin{array}{l}\text { Atividades da } \\
\text { indústria } \\
\text { PINTEC } 2011\end{array}$} & \multicolumn{11}{|c|}{ Empresas } \\
\hline & \multirow{4}{*}{ Total } & \multicolumn{10}{|c|}{ Que não implementaram produto ou processo e sem projetos } \\
\hline & & \multirow{2}{*}{\multicolumn{2}{|c|}{ Total }} & \multicolumn{8}{|c|}{ IO } \\
\hline & & & & \multicolumn{2}{|c|}{ Técnicas de gestão } & \multicolumn{2}{|c|}{$\begin{array}{l}\text { Técnicas de gestão } \\
\text { ambiental }\end{array}$} & \multicolumn{2}{|c|}{$\begin{array}{l}\text { Organização do } \\
\text { trabalho }\end{array}$} & \multicolumn{2}{|c|}{ Relações externas } \\
\hline & & Qt. & $\%$ & Qt. & $\%$ & Qt. & $\%$ & Qt. & $\%$ & Qt. & $\%$ \\
\hline \multirow{2}{*}{ Total } & 128699 & 79591 & $61.8 \%$ & 22524 & $17.5 \%$ & 15579 & $12.1 \%$ & 19341 & $15.0 \%$ & 9777 & $7.6 \%$ \\
\hline & $100.0 \%$ & $100.0 \%$ & & $100.0 \%$ & & $100.0 \%$ & & $100.0 \%$ & & $100.0 \%$ & \\
\hline \multirow{2}{*}{$\begin{array}{l}\text { Indústrias de } \\
\text { transformação }\end{array}$} & 114212 & 70584 & $61.8 \%$ & 19554 & $17.1 \%$ & 14387 & $12.6 \%$ & 16632 & $14.6 \%$ & 8799 & $7.7 \%$ \\
\hline & $88.7 \%$ & $88.7 \%$ & & $86.8 \%$ & & $92.3 \%$ & & $86.0 \%$ & & $90.0 \%$ & \\
\hline
\end{tabular}

Fonte: IBGE, Diretoria de Pesquisas, Coordenação de Indústria, Pesquisa de Inovação 2011. 
Das empresas que não implementaram IT, mas que realizaram IO, considerando-se os tipos de atividades de IO realizadas, tem-se que $17,5 \%$ do total das empresas pesquisadas implementaram "inovações em técnicas de gestão", 12,1\% implementaram "inovações em técnicas de gestão ambiental", 15,0\% implementaram "inovações na organização do trabalho" e 7,6\% implementaram "inovações em relações externas".

Realizando-se a análise da atividade das indústrias de transformação, pode-se verificar que do total de empresas pesquisadas pertencentes a este setor, que $17,1 \%$ dessas empresas implementaram "inovações em técnicas de gestão", 12,6\% implementaram "inovações em técnicas de gestão ambiental", $14,6 \%$ implementaram "inovações na organização do trabalho" e 7,7\% implementaram "inovações nas relações externas".

\section{Considerações finais}

Este estudo teve como objetivo apresentar um panorama acerca dos aspectos mais importantes da IO considerados pelas empresas de países da Comunidade Europeia (CE), com base na Community Inovation Survey, e pelas empresas situadas no Brasil, com base na Pesquisa de Inovação (PINTEC). Observou-se que os países da $\mathrm{CE}$ que possuem a maior quantidade de empresas pesquisadas e também a maior quantidade de empresas que realizaram inovações, foram os países que realizaram menos IO em relação aos demais, com destaque para a Alemanha (79,3\% das empresas realizaram inovações, porém 19\% das empresas inovadoras realizaram somente IO e de marketing). Tomando como exemplo a Alemanha, seu alto percentual de empresas que realizam inovações e o baixo percentual de empresas que realizam somente IO ou somente inovações de produto ou somente de processo, mostra que essas empresas realizaram não só um tipo de inovação, mas se dedicaram à realização de inovações de produto, processo, IO e de marketing concomitantemente.

Ao comparar a quantidade de empresas pesquisadas no Brasil e na $\mathrm{CE}$, é possível notar que a quantidade de empresas pesquisadas no Brasil (PINTEC 2011 - 128.699 empresas) é superior que a quantidade de empresas do país que mais possuiu empresas pesquisadas (Alemanha - CIS 7 127.073 empresas). Por outro lado, o percentual de empresas que realizaram inovações no Brasil (PINTEC 2011 - 38,2\%) é consideravelmente inferior que o da Alemanha (CIS 7 - 79,3\%), se aproximando do percentual de empresas que realizaram inovações na Espanha (CIS 7 - 41,2\%) e inferior ao percentual médio das empresas da CE (27 países - 52,9\%).

Realizando-se a comparação do percentual total de empresas no Brasil que realizaram somente IO e/ou de marketing (PINTEC 2011 - 34,9\% do total de empresas pesquisadas) com o da somatória das empresas que realizaram somente IO e/ou de marketing da CE (27 países - CIS 7 $14,0 \%$ do total de empresas pesquisadas), foi possível observar que, percentualmente, as empresas situadas no Brasil, que realizam somente IO e/ou de marketing, é superior em 20,9 pontos percentuais as empresas pertencentes à CE.

Comparando-se o percentual de empresas que realizaram somente IO e/ou de marketing situadas no Brasil em relação ao total de empresas pesquisadas, com os percentuais das empresas dos países com grande quantidade de empresas pesquisadas, temos, portanto: Brasil $(34,9 \%)$, França $(19,2 \%)$, Turquia $(16,2 \%)$, Itália $(15,9 \%)$, Alemanha $(15,1 \%)$ e Espanha $(12,2 \%)$.

Realizou-se a comparação dos resultados das empresas situadas na CE, com base na CIS, com os dados das empresas situadas no Brasil, obtidos da PINTEC. Observou-se que o percentual das empresas situadas no Brasil que realizaram somente IO e/ou marketing é superior em comparação com os principais países da CE. Entende-se que as empresas situadas no Brasil realizam mais $\mathrm{IO}$ e/ou de marketing que as empresas dos principais países da CE.

O percentual de empresas que realizaram somente IO e/ou de marketing situadas no Brasil é superior ao dos principais países da Comunidade Europeia, porém, alguns países, como a Alemanha por exemplo, possuem alto percentual de empresas que realizam inovações e baixo 
percentual para aquelas que realizam somente um tipo de inovação (seja somente IO, produto, processo). Isso sugere deduzir que essas empresas se dedicam em realizar, concomitantemente, inovações de produto, processo, IO e de marketing, trabalhando em várias frentes de inovação ao mesmo tempo, seja de qual tipo for, buscando a evolução constante da empresa, de certa forma, não priorizando um ou outro tipo de inovação, mas trabalhando todas em conjunto, o que fazem com que elas estejam "imbricadas" umas nas outras, tornando-se, possivelmente "indissociáveis".

As empresas situadas no Brasil possuem percentual superior em todas as faixas de pessoal ocupado, em comparação com os países selecionados, em relação a realização de, somente, IO e/ou de marketing. Isso sugere que as empresas situadas no Brasil realizam mais IO e/ou de marketing que as empresas da Comunidade Europeia. Foi possível observar, nas empresas situadas no Brasil, que quanto maior o tamanho da empresa, maior é a importância dada às técnicas de gestão.

Sugere-se para estudos futuros, avaliar os resultados da IO considerando o setor, bem como os demais tipos de inovação (produto, processo, marketing). Outra sugestão é a análise regional, dentro de cada país, dos aspectos apresentados neste estudo. Como limitações podem-se observar o estudo nos países selecionados, ficando de fora da pesquisa outros países, não podendo-se generalizar os resultados aqui apresentados. Outra delimitação foi o fator temporal, o que foca a pesquisa em duas edições da CIS e não em todas as disponibilizadas, que, inclusive, pode-se sugerir como estudo futuro.

\section{Agradecimentos}

Os autores agradecem ao apoio da FAPEMIG e do CNPq.

\section{Referências}

FREEMAN, C. The economics of industrial innovation. MIT Press, 1974.

FREEMAN, C. Technology and economic performance: lessons from Japan. Pinters Publishers, 1987.

GALLEGO, J.; RUBALCABA, L.; HIPP, C. Organizational innovation in small European firms: a multidimensional approach. International Small Business Journal, v. 31, fev. 2012.

GANTER, A.; HECKER, A. Configurational paths to organizational innovation: qualitative comparative analyses of antecedents and contingencies. Journal of Business Research, 2013.

GUAN, J.; LIU, J. Integrated innovation between technology and organization. International Journal of Innovation Management, v. 4, n. 4, 2007.

GUNDAY, G.; ULUSOY, G.; KILIC, K.; ALPKAN, L. Effects of innovation types on firm performance. International Journal of Production Economics, v. 133, n. 2, p. 662-676, 2011.

IBGE - Instituto Brasileiro de Geografia e Estatística. Pesquisa de inovação - PINTEC 2011. Rio de Janeiro: IBGE, 2013.

LAM, A. The Oxford handbook of innovation. Oxford, UK: Oxford University, Press, 2005.

LUNDVALL, B.; NIELSEN, P. Innovation, learning organisation and industrial relations. DRUID Working Papers, n. 03-07 (mimeo). Copenhagen: Danish Research Unit for Industrial Dynamics, 2002.

LYNCH, L. M. The adoption and diffusion of organizational innovation: evidence for the U.S. economy. National Bureau of Economic Research (NBER), Working Paper n. 13156, Cambridge, jun., 2007.

OECD. Proposed guidelines for collecting and interpreting technological innovation data: Oslo Manual. Paris: OECD, 2005. 
OCDE. Manual de Oslo: diretrizes para coleta e interpretação de dados sobre inovação. $3^{\mathrm{a}}$ ed. Rio de Janeiro: FINEP, 2005.

PAVITT, K. Sectorial patterns of technical change: towards a taxonomy and a theory. Research Policy, v. 13, 1984.

PEREZ, C. Technological revolutions and techno-economic paradigms. Working papers in Technology Governance and Economic Dynamics no. 20. The other canon foundation, Norway Tallinn University of Technology: Tallinn, January 2009.

PORTER, M. The comparative advantage of nations. Macmilan, 1990.

SAPPRASERT, K; CLAUSEN, T. H. Organizational innovation and its effects. Industrial and Corporate Change, v. 21, n. 5, p. 1283-1305, August, 2012.

SCHUMPETER, J. A. Teoria do desenvolvimento econômico. São Paulo: Editora Abril Cultural, 1982.

SUBRAMANIAN, A.; NILAKANTA, S. Organizational Innovativeness: exploring the relationship between organizational determinants of innovation, types of innovations, and measures of organizational performance. International Journal Management Science, v. 24, n. 6, p. 631-647, 1996.

TIGRE, P. B. Paradigmas tecnológicos e teorias econômicas da firma. Revista Brasileira de Inovação, v. 4, n. 1, 2005.

TIGRE, P. B. Gestão da inovação: a economia da tecnologia do Brasil. Rio de Janeiro: Elsevier, 2006. 